\title{
INI1-negative colorectal undifferentiated carcinoma with rhabdoid features and postoperative rapidly growing liver metastases: a case report and review of the literature
}

Masatsugu Kojima ${ }^{1 *} \mathbb{0}$, Toru Miyake ${ }^{1}$, Tomoyuki Ueki ${ }^{1}$, Hiroyuki Ohta ${ }^{2}$, Ryoji Kushima ${ }^{3}$, Masanori Shiohara ${ }^{3}$, Hiroo Mizuta ${ }^{4}$, Hiroya lida ${ }^{1}$, Tsuyoshi Yamaguchi' , Sachiko Kaida ${ }^{1}$, Katsushi Takebayashi ${ }^{1}$, Hiromitsu Maehira ${ }^{1}$, Yusuke Nishina ${ }^{2}$, Tomoharu Shimizu${ }^{5}$, Eiji Mekata ${ }^{2}$ and Masaji Tani ${ }^{1}$

\begin{abstract}
Background: Malignant tumors with rhabdoid features are extremely rare. They can occur in various organs, including the gastrointestinal tract, with common clinical features of high malignancy and poor prognosis.

Case presentation: A 41-year-old man visited our hospital complaining of lower abdominal pain and fever. Computed tomography (CT) revealed two wall-thickening lesions in the rectum and sigmoid colon, with the latter invading the small intestine and abdominal wall. Lymph nodes were swollen in the sigmoid mesocolon and at the roots of the inferior mesenteric artery. Colonoscopy revealed a circular type 3 lesion in the sigmoid colon and a semicircular type 2 lesion in the rectum. Biopsies of the sigmoid colon and rectum lesions revealed poorly and moderately differentiated adenocarcinoma cells, respectively. The sigmoid colon, rectum, invaded small intestine, and abdominal wall were resected; lymph node dissection was also performed. Histopathological finding of the sigmoid colon lesion revealed that the tumor cells had poor connectivity with each other, and each cell had eosinophilic cytoplasm and a polymorphic nucleus. These characteristics are termed rhabdoid features, because the morphology of these cells is similar to that of rhabdomyosarcoma tumor cells. Immunohistochemical examination showed that the tumor cells were positive for both epithelial (cytokeratin AE1/AE3) and mesenchymal cell markers (vimentin); however, they were negative for integrase interactor 1 (INI1). Therefore, the sigmoid colorectal cancer was diagnosed as an INI1-negative undifferentiated carcinoma with rhabdoid features. The patient continued to experience high fever after surgery; thus, we performed an abdominal CT scan that revealed cystic lesions in the liver 4 days after surgery. These were absent in the positron emission tomography (PET)-CT scan performed 14 days before surgery. These tumors grew rapidly, and fine needle aspiration cytology revealed that they were undifferentiated carcinomas compatible with metastatic lesions from the undifferentiated carcinoma with rhabdoid features from the sigmoid colon. Chemotherapy was administered but was not effective. The patient died 60 days after surgery.
\end{abstract}

\footnotetext{
*Correspondence: mkojima@belle.shiga-med.ac.jp

1 Division of Gastrointestinal, Breast and General Surgery, Department of Surgery, Shiga University of Medical Science, Tsukinowa-cho, Seta, Otsu, Shiga 520-2192, Japan

Full list of author information is available at the end of the article
}

(c) The Author(s) 2021. Open Access This article is licensed under a Creative Commons Attribution 4.0 International License, which permits use, sharing, adaptation, distribution and reproduction in any medium or format, as long as you give appropriate credit to the original author(s) and the source, provide a link to the Creative Commons licence, and indicate if changes were made. The images or other third party material in this article are included in the article's Creative Commons licence, unless indicated otherwise in a credit line to the material. If material is not included in the article's Creative Commons licence and your intended use is not permitted by statutory regulation or exceeds the permitted use, you will need to obtain permission directly from the copyright holder. To view a copy of this licence, visit http://creativecommons.org/licenses/by/4.0/. 
Conclusions: INI1-negative colorectal undifferentiated carcinomas with rhabdoid features are extremely rare, have high histological malignancy, and a poor prognosis. Chemotherapy is not effective. Effective systemic therapy is desired.

Keywords: INI1/SMARCB1, Colorectal undifferentiated carcinoma, Rhabdoid feature, Rhabdoid tumor

\section{Background}

Malignant tumors with rhabdoid features are extremely rare. They occur in various organs, including the gastrointestinal tract, and they have common clinical features such as high malignancy and poor prognosis [1]. Integrate interactor 1 (INI1) is a protein encoded by the tumor suppressor gene SMARCB1. INI1-deficient colorectal carcinoma has a high histological malignancy, large tumor diameter, and poor prognosis [2]. Approximately half of malignant tumors with rhabdoid features in the gastrointestinal tract lack INI1 expression [1]. Here, we report the case of an extremely rare INI1-negative undifferentiated colorectal carcinoma with rhabdoid features in the sigmoid colon, which caused the rapid progression of liver metastases after surgery.

\section{Case presentation}

A 41-year-old man visited our hospital complaining of lower abdominal pain and fever for 2 weeks. He did not have a remarkable medical history. The detailed family history was unknown, because he and his parents were not close to their relatives. He had no siblings or children, and what they knew for sure was that his parents and grandparents had no history of cancer. Laboratory findings revealed mild inflammation; WBC was 8,940 / $\mu \mathrm{L}$, and CRP level was $1.08 \mathrm{mg} / \mathrm{dL}$. He also had mild anemia with his hemoglobin level at $11.1 \mathrm{~g} / \mathrm{dL}$. The levels of the tumor markers, CEA and CA19-9 were within the normal range; moreover, sIL-2R levels were normal. The computed tomography (CT) scan showed two wallthickening lesions in the rectum and sigmoid colon, with the latter invading the small intestine and abdominal wall (Fig. 1a). Lymph nodes were swollen in the sigmoid mesocolon and at the roots of the inferior mesenteric artery, which had sac-like degeneration inside (Fig. 1b, c). A colonoscopy revealed a circular type 3 lesion in the sigmoid colon and a semicircular type 2 lesion in the rectum (Fig. 2a, b). The biopsy result of rectum lesion was moderately differentiated adenocarcinoma; and the biopsy of the sigmoid colon lesion showed that round cells with swollen nuclei and eosinophilic cytoplasm proliferated separately with each other. We suspected that the sigmoid colon lesion was poorly differentiated adenocarcinoma. A positron emission tomography (PET)-CT scan showed fluorodeoxyglucose (FDG) accumulation in the sigmoid colon lesion, rectal lesion, and swollen lymph
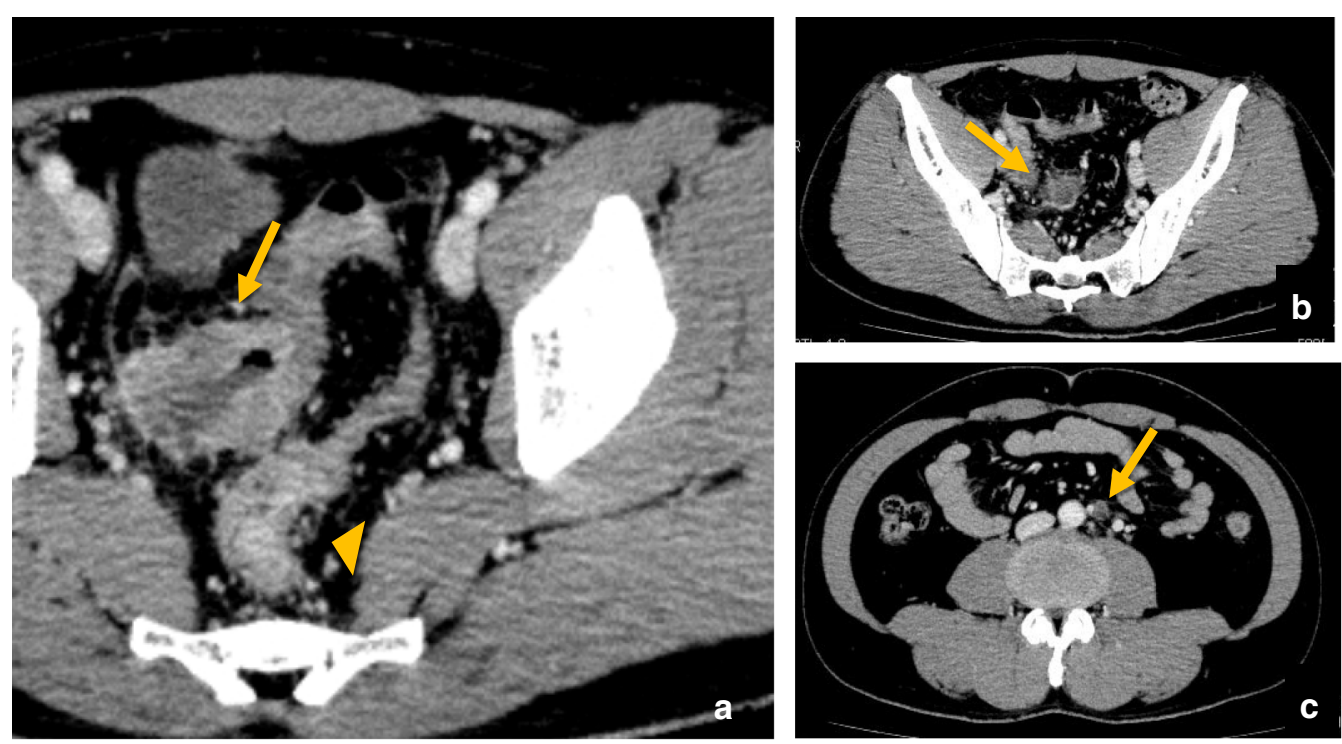

Fig. 1 Computed tomography (CT) scan showed two wall-thickening lesions in the rectum (arrowhead) and sigmoid colon (arrow), with the latter invading the small intestine and abdominal wall (a). Lymph nodes were swollen in the sigmoid mesocolon (b) and at the roots of the inferior mesenteric artery $(\mathbf{c})$. Some of the swollen lymph nodes had sac-like degeneration inside (b) 

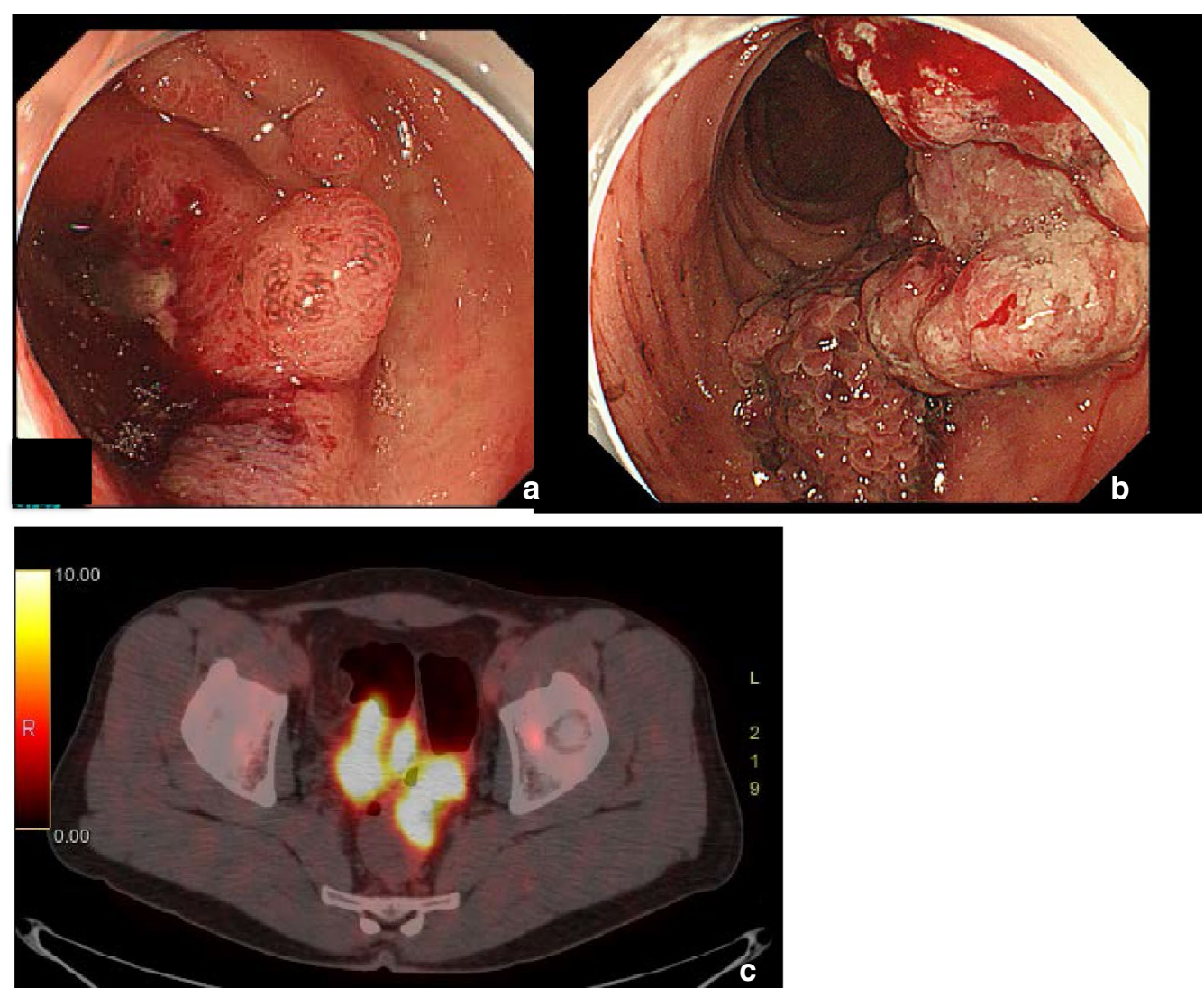

Fig. 2 Colonoscopy revealed a circular type 3 lesion in the sigmoid colon (a) and a semicircular type 2 lesion in the rectum (b). A positron emission tomography (PET)-CT scan showed fluorodeoxyglucose (FDG) accumulation in the sigmoid colon lesion, rectal lesion, and swollen lymph nodes (c)

nodes; however, no distant metastases were demonstrated (Fig. 2c). We preoperatively diagnosed the case as rectal and sigmoid colon cancer with lymph node metastases without distant metastases. Sigmoidectomy, low anterior resection, and lymph node dissection were performed. The sigmoid colon cancer invaded into the small intestine, abdominal wall, and vas deferens, which were resected together. The tumor and sigmoid mesocolon were markedly swollen and occupied the pelvic entrance; moreover, the sigmoid mesocolon was strongly adhered to the retroperitoneum due to inflammation. White nodules that were present in the sigmoid mesocolon were removed; we suspected that these might be involved in peritoneal dissemination. The excised specimens are shown in Fig. 3.

Histopathological findings revealed that the rectal cancer was a typical moderately differentiated adenocarcinoma. However, the sigmoid colon cancer had different features including tumor cells with polymorphic nuclei and eosinophilic cytoplasm. These cells had poor connectivity with each other. These characteristics are called rhabdoid features, because the

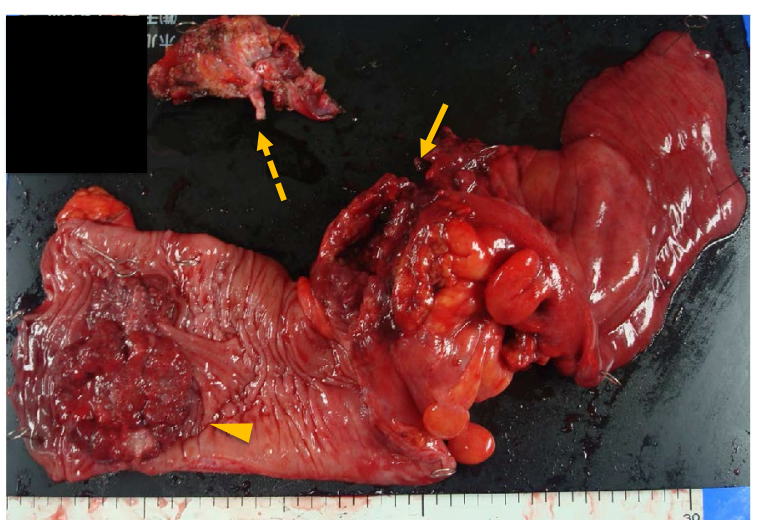

Fig. 3 Macroscopic findings of the resected specimen. A circumferential type 3 lesion was found in the sigmoid colon (arrow), and a semicircular type 2 lesion was found in the rectum (arrowhead). The sigmoid colon lesion invaded the small intestine, vas deferens (dashed arrow), which were resected together 
morphology of these cells is similar to that of rhabdomyosarcoma tumor cells (Fig. 4a). Immunohistochemical examination showed that the tumor cells were positive for both epithelial (cytokeratin AE1/AE3) and mesenchymal cell markers (vimentin). However, these cells were negative for INI1, which is normally expressed in the nucleus of cells (Fig. 4b-e). Therefore, the sigmoid colon cancer was diagnosed as an INI1-negative undifferentiated carcinoma with rhabdoid features. Moreover, CDX2, which is a marker of
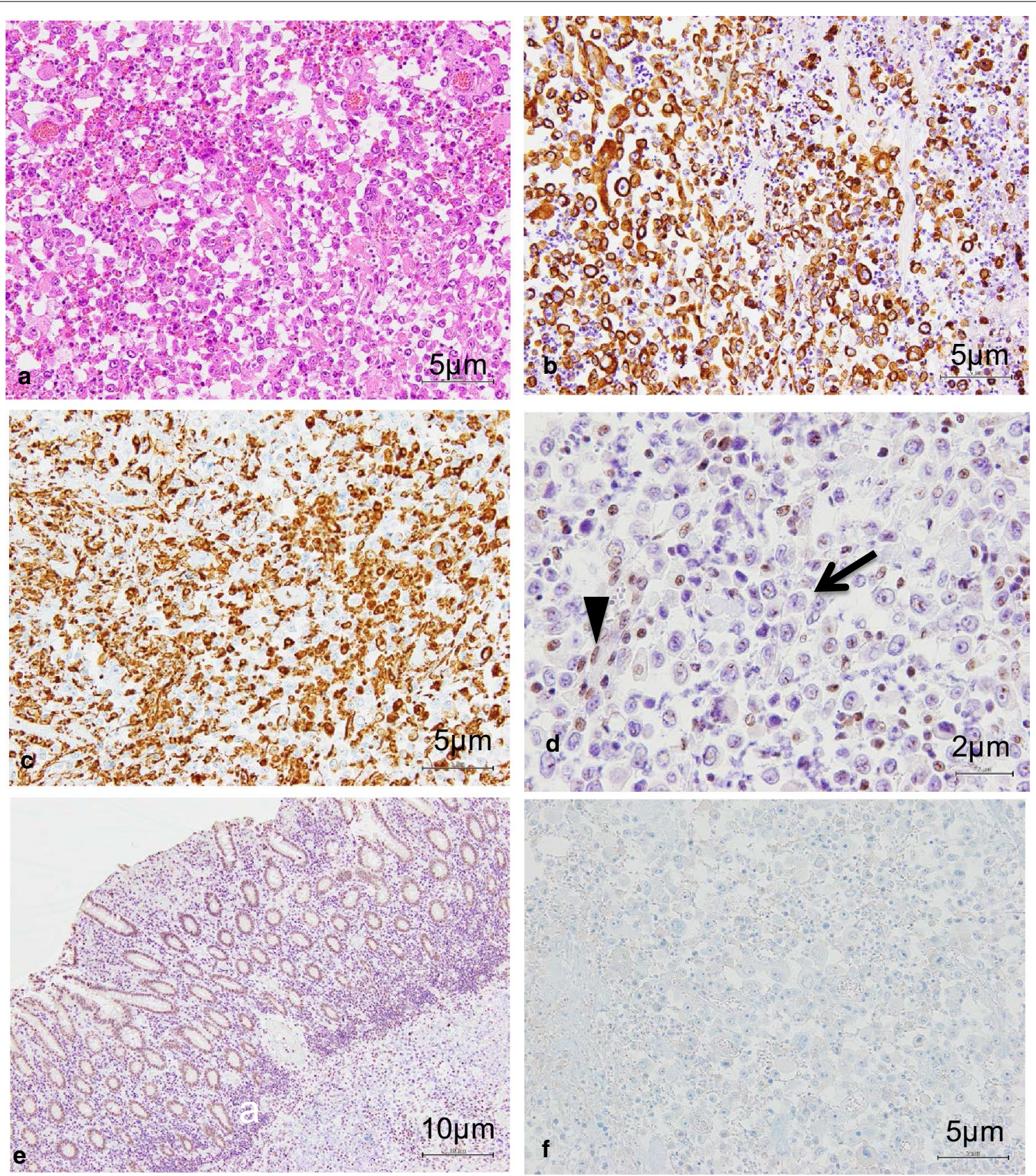

Fig. 4 Sigmoid colon tumor cells had polymorphic nuclei and eosinophilic cytoplasm. These cells had poor connectivity with each other. These characteristics are called rhabdoid features, because the morphology of these cells is similar to that of rhabdomyosarcoma tumor cells $($ HE $\times 200)(a)$. Immunohistochemical examination showed that the tumor cells were positive for both epithelial (cytokeratin AE1/AE3) (× 200) (b) and mesenchymal cell markers (vimentin) (× 200) (c). These tumor cells were negative for INI1 (arrow), on the other hand, the surrounding non-neoplastic cells were positive for INI1 (arrowhead) $(\times 400)($ d). Contrast to the tumor cells, non-tumor crypt epithelium cells were INI1 positive $(\times 100)(\mathbf{e})$. The tumor cells were negative for CDX2, which is a marker of colonocytes differentiation $(\times 200)(\mathbf{f})$ 
colonocytes differentiation, was negative (Fig. 4f); and Ki67, which shows proliferative ability, was as high as $40 \%$. The white nodules on the sigmoid mesocolon were diagnosed as peritoneal dissemination, and the multiple lymph nodes were also diagnosed as metastatic. The final diagnosis was sigmoid colon cancer; pT4b (small intestine, abdominal wall) N2b M1c pStage IVC (peritoneal dissemination), and rectal cancer; pT3(SS) N0.

On day 4 after surgery, the patient continued to experience high fever of $\geq 38{ }^{\circ} \mathrm{C}$. To examine the presence of lesions that could be causing the fever, an abdominal CT scan was performed, which revealed cystic lesions in liver segments S1 and S7 (Fig. 5a). These lesions were absent in the PET-CT scan performed 14 days before surgery. These lesions grew rapidly 11 days after surgery, as confirmed by $\mathrm{CT}$ (Fig. 5b); therefore, we suspected that the lesions were liver abscesses or metastases. A fine needle aspiration cytology revealed undifferentiated carcinoma cells compatible with metastatic lesions from the undifferentiated carcinoma with rhabdoid features from the sigmoid colon. Chemotherapy, comprising modified FOLFOX6 (oxaliplatin and an infusion of 5-fluorouracil/leucovorin $(5 \mathrm{FU} / \mathrm{LV})$ ) plus bevacizumab, was administered on postoperative day 22. However, after the second course, CT showed that the number and size of the liver metastases had progressed by postoperative day 47 (Fig. 5c). The molecular analysis indicated that the sigmoid colon cancer was KRAS and NRAS-wild, BRAFV600E-mutant, and microsatellite stable (MSS). The chemotherapy regimen was then changed to FOLFOXIRI (irinotecan, oxaliplatin, and an infusion of $5 \mathrm{FU} / \mathrm{LV}$ ) plus bevacizumab; however, the general condition of the patient rapidly deteriorated, and he died on postoperative day 60 .

\section{Discussion}

Malignant tumors with rhabdoid features are extremely rare and were first reported by Beckwith and Palmer in 1978 as a sarcomatoid subtype of Wilms tumor in the kidneys of fetuses and children [3]. Since then, it has been reported that malignant tumors with rhabdoid features can occur in various organs other than the kidneys in adults. Despite this diversity, these tumors have common clinical features, such as extremely high malignancy and poor prognosis $[1,2]$. Malignant tumors with rhabdoid features are associated with carcinoma, sarcoma, and carcinosarcoma, depending on the tissue it develops in $[4,5]$. In colorectal adenocarcinomas, they are named undifferentiated carcinomas with rhabdoid features.

Malignant tumors with rhabdoid features have cells with eosinophilic cytoplasm, oval or circular nuclei with prominent nucleoli, and vitreous inclusion bodies [6] Although these tumors are morphologically sarcomalike, immunohistochemical examination shows them to be negative for muscular markers and positive for epithelial (e.g., cytokeratin AE1/AE3) and mesenchymal cell markers (e.g., vimentin) [7]. Tumor cells have low adhesion, high mitotic potential, and are prone to infiltrate other organs. These histological features were also observed in the present case; the liver metastases discovered after surgery increased extremely rapidly and aggressively in both number and size. Furthermore, we detected cystic degeneration due to central necrosis, which was similar to liver abscesses. A preoperative CT scan revealed that some lymph node metastases showed cystic degeneration.
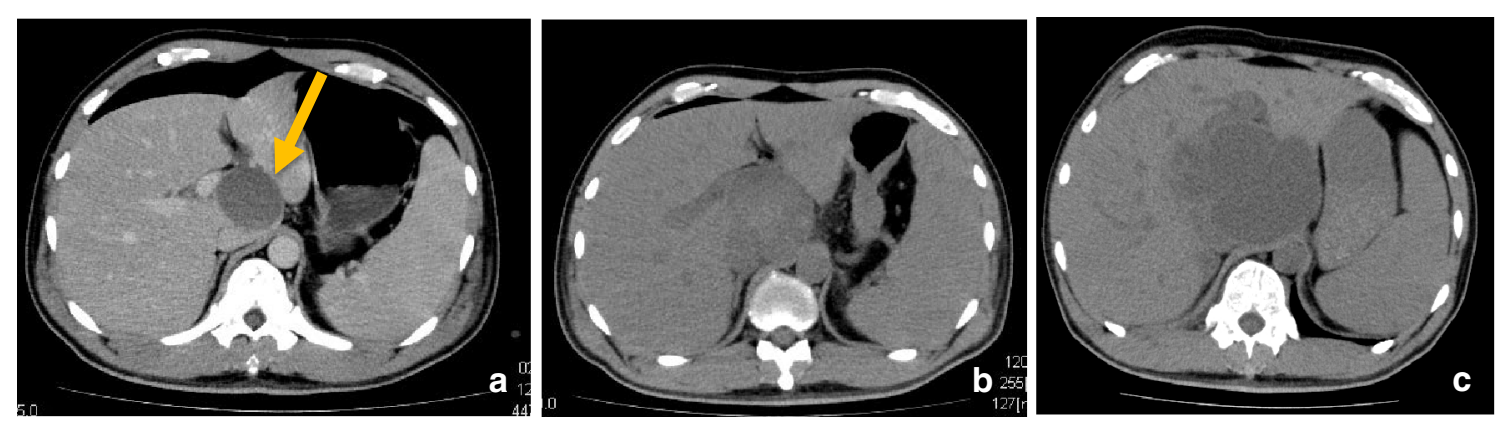

Fig. 5 Abdominal CT revealed new cystic lesions appeared in liver segment S1 (a, arrow) and S7 (not shown) 4 days after surgery. These lesions grew rapidly 11 days after surgery $(\mathbf{b})$. The fine needle aspiration cytology revealed that these were metastatic lesions from the undifferentiated carcinoma with rhabdoid features. Chemotherapy was ineffective and they continued to progress 47 days after surgery (c) 
Malignant tumors with rhabdoid features are of two types: the first is entirely composed of undifferentiated carcinoma cells (pure type), whereas the second consists of not only undifferentiated carcinoma cells but also carcinoma cells with a high degree of differentiation in developing organs (composite type). The presence of composite type suggests that the rhabdoid features could have been developed from dedifferentiating from differentiated malignant cells $[1,8]$.

INI1 is a protein encoded by the tumor suppressor gene, SMARCB1. It constitutes the switch/sucrose nonfermentable (SWI/SNF) complex, which is thought to function in an ATP-dependent manner to cause a conformational change in the nucleosome that alters histoneDNA binding, thereby facilitating transcription factor access [9-11]. INI1 is normally expressed in the nucleus of cells; however, its expression is known to be lack or reduced in rhabdoid tumor cells $[9,10]$. In a study that examined 3051 cases of colorectal cancers, the INI1encoding gene was deleted in 14 cases $(0.46 \%)$ [2]. INI1deficient colorectal carcinomas have a high histological malignancy, large tumor diameter, and poor prognosis [2]. Approximately half of gastrointestinal undifferentiated carcinomas with rhabdoid features lack INI1 expression [1]; INI1-encoding gene deletion appears to be crucial for the development of rhabdoid features in some cases $[1,10,11]$.

Large intestine-derived malignant tumors with rhabdoid features are rare [12], and to date, only 28 cases (including the current case) of colorectal undifferentiated carcinoma with rhabdoid features have been reported (Table 1) [1, 5, 12-36]. These cases have been reported in 17 men and 11 women. The average age of these patients was 64.5 years (range: $23-87$ years). The right colon (cecum to transverse colon) was the most common site of carcinoma occurrence in 16 cases (57.1\%), followed by the left colon (descending colon to sigmoid colon) in 6 cases $(21.4 \%)$, and the rectum in 6 cases $(21.4 \%)$. The average tumor diameter was $9.4 \mathrm{~cm}$ (range, $4-17 \mathrm{~cm}$ ). Of all, the lymph nodes metastases were reported in 20 cases (71.4\%), the liver in 7 cases (25\%), peritoneal dissemination in 4 cases $(14.3 \%)$, and the lungs in 2 cases (7.1\%). Regarding INI1, 57\% reported cases were negative, which was almost the same rate that reported before in gastrointestinal tract undifferentiated cancer with rhabdoid features [1].

Raf is a kinase that is a member of the Ras/Raf/MAPK pathway, and when this pathway is activated, it enhances the cell cycle. In BRAF, which is a member of the RAF family, a missense mutation (V600E) of exon 15 codon
600 activates the downstream signal [37]. About 7\% of colorectal cancers have this mutation, and their prognosis are known to be poor [38]. In addition, such BRAF mutant colorectal cancer was reported to be more common in sporadic microsatellite instability (MSI) -high right-sided colon cancers [39]. Regarding undifferentiated colorectal cancer with Rhabdoid features, BRAF V600VE mutation was observed in 6 of 7 reported cases (Table 1). We supposed that there may be some correlation between BRAF mutation and rhabdoid features in colorectal cancers. The elucidation of the molecular mechanism is considered to be an issue for the future. On the other hand, MSI was examined in only 2 cases including our case. Both cases were microsatellite stable, but the number of cases was too small to make any conclusion. Along with the accumulation of cases, elucidation of the correlation between MSI status and the rhabdoid feature is also a future issue.

The colorectal undifferentiated carcinoma with rhabdoid features reported were divided into 13 and 15 cases of the composite and pure types, respectively. The survival curve for these cases is shown in Fig. 6. The median overall survival (OS) of patients with undifferentiated carcinoma with rhabdoid features was 3 months, indicating an extremely poor prognosis. Comparison of the OS of patients with the pure and composite types showed no significant difference $(p=0.123)$. Although there is a limitation that various clinical stages are included in each type group, it suggests that the presence of rhabdoid features would be responsible for the poor survival [1]. The pure type might simply be a case in which the original cancer lesion could not be found in specimens, because it was too small. Although chemotherapy was administered to 9 patients with metastasis, 8 patients died within 1 year. This suggests that the effect of chemotherapy is limited. It has been reported at the experimental level in vitro and in vivo that gefitinib, a selective tyrosine kinase receptor inhibitor, is effective for treating malignant tumors with rhabdoid features [40]. It is considered that further effective clinical trials for malignant tumors with rhabdoid features is required.

\section{Conclusion}

INI1-negative colorectal undifferentiated carcinomas with rhabdoid features are extremely rare, and they have aggressive histological malignancy and poor survival. Chemotherapy is not effective at present; therefore, future clinical trials is required to improve the survival. 


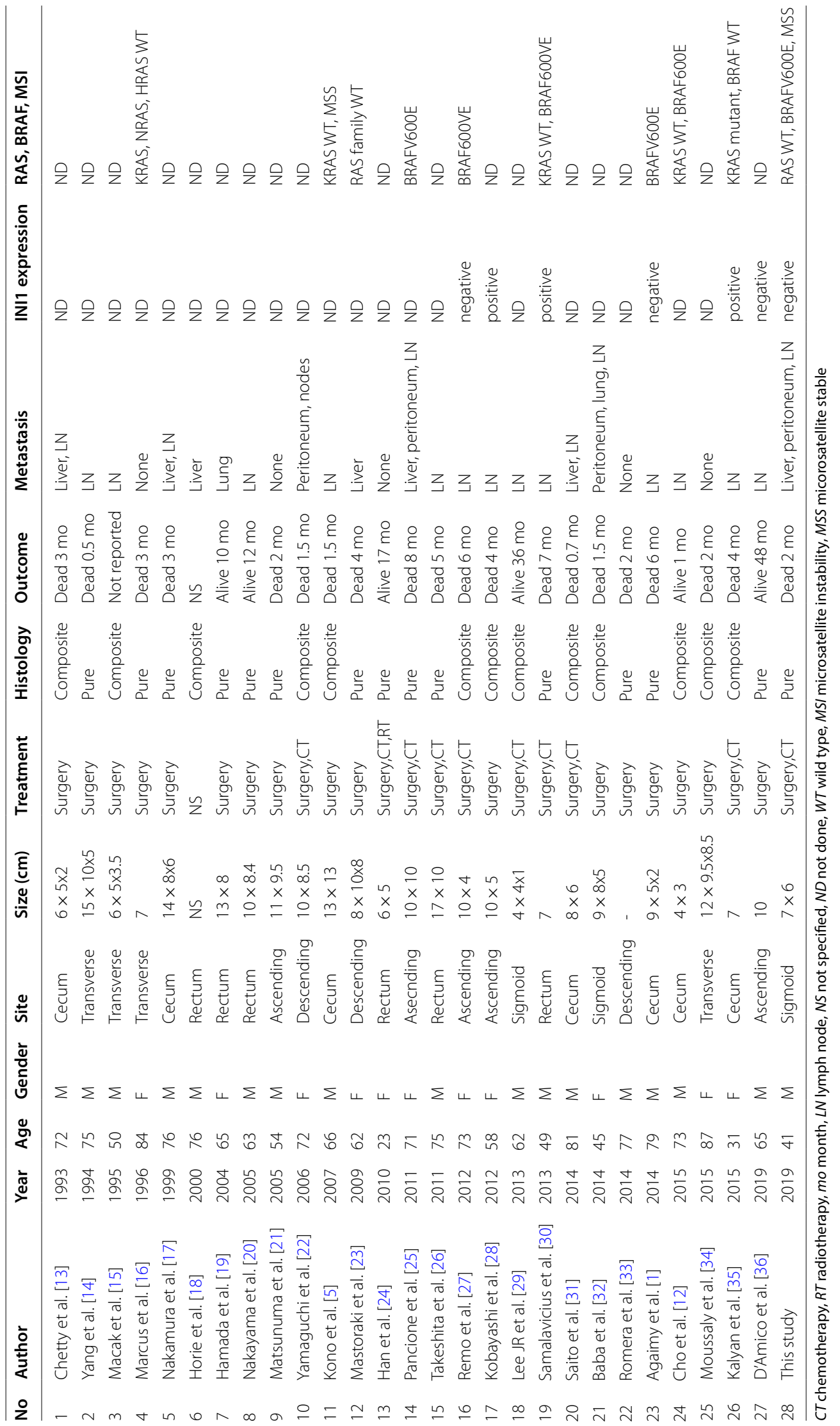



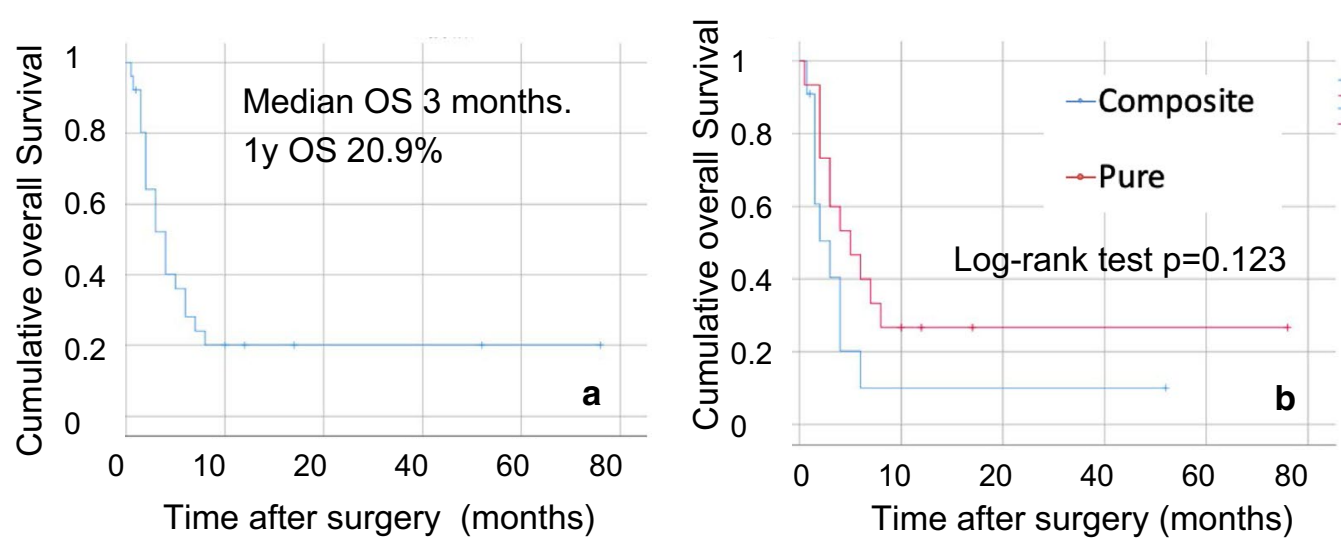

Fig. 6 Kaplan-Meier survival analyses. (a) Overall survival (OS) of all patients with colorectal undifferentiated carcinoma with rhabdoid features was 3 months after surgery. The 1 -year survival rate was $20.9 \%$. (b) Comparison of patients with the pure and composite types showed no significant difference $(p=0.123)$

\section{Abbreviations}

CT: Computed tomography; WBC: White blood cell; CRP: C-reactive protein; CEA: Carcinoembryonic antigen; CA19-9: Carbohydrate antigen 19-9; sIL-2R: Soluble interleukin-2 receptor; INI1: Integrate interactor 1; PET: Positron emission tomography; FDG: Fluorodeoxyglucose; 5FU/LV: 5-Fluorouracil/ leucovorin.

\section{Acknowledgements}

All authors have no financial support, including technical assistance and advice, to acknowledge.

\section{Authors' contributions}

MK wrote the manuscript. MK and $\mathrm{HO}$ performed the operation. MK, $\mathrm{HO}, \mathrm{HM}$ and EM managed the patient's perioperative course. RK and MS contributed to the drafting of the pathological findings portion of the manuscript. MT gave final approval of this manuscript. All the authors participated in the report's design and coordination, and helped draft the manuscript. All the authors have read and approved the final manuscript.

\section{Funding}

No funding was received in support of this study.

\section{Availability of data and materials}

The data sets supporting the conclusions of this article are included within the article.

\section{Declarations}

Ethics approval and consent to participate

Not applicable.

\section{Consent for publication}

Consent has been obtained in Japanese from the patient to publish clinical data and imaging for the purposes of this case report.

\section{Competing interests}

The authors declare that they have no competing interests.

\section{Author details}

${ }^{1}$ Division of Gastrointestinal, Breast and General Surgery, Department of Surgery, Shiga University of Medical Science, Tsukinowa-cho, Seta, Otsu, Shiga 520-2192, Japan. ${ }^{2}$ Department of Comprehensive Surgery, Shiga University of Medical Science, Tsukinowa-cho, Seta, Otsu, Shiga 520-2192, Japan. ${ }^{3}$ Department of Pathology, Shiga University of Medical Science, Tsukinowa-cho, Seta, Otsu, Shiga 520-2192, Japan. ${ }^{4}$ Department of Comprehensive Internal Medicine, Shiga University of Medical Science, Tsukinowa-cho, Seta, Otsu, Shiga 520-2192, Japan. ${ }^{5}$ Medical Safety Section, Shiga University of Medical Science, Tsukinowa-cho, Seta, Otsu, Shiga 520-2192, Japan.

Received: 21 January 2021 Accepted: 19 April 2021

Published online: 27 April 2021

\section{References}

1. Agaimy A, Rau TT, Hartmann A, Stoehr R. SMARCB1 (INI1)-negative rhabdoid carcinomas of the gastrointestinal tract: clinicopathologic and molecular study of a highly aggressive variant with literature review. Am J SurgPathol. 2014:38(7):910-20.

2. Wang J, Andrici J, Sioson L, Clarkson A, Sheen A, Farzin M, et al. Loss of INI1 expression in colorectal carcinoma is associated with high tumor grade, poor survival, BRAFV600E mutation, and mismatch repair deficiency. Hum Pathol. 2016;55:83-90.

3. Beckwith JB, Palmer NF. Histopathology and prognosis of Wilmstumors: results from the First National Wilms'Tumor Study. Cancer. 1978;41(5):1937-48

4. Kohashi K, Oda Y. Oncogenic roles of SMARCB1/INI1 and its deficient tumors. Cancer Sci. 2017;108(4):547-52.

5. Kono T, Imai Y, Imura J, Ono Y, Hagiwara S, Taira K, et al. Cecal adenocarcinoma with prominent rhabdoid feature: report of a case with immunohistochemical, ultrastructural, and molecular analyses. Int J SurgPathol. 2007:15(4):414-20.

6. Frierson HF, Mills SE, Innes DJ. Malignant rhabdoidtumor of the pelvis Cancer. 1985:55(9):1963-7.

7. Kodet R, Newton WA, Sachs N, Hamoudi AB, Raney RB, Asmar L, et al. Rhabdoidtumors of soft tissues: a clinicopathologic study of 26 cases enrolled on the Intergroup Rhabdomyosarcoma Study. Hum Pathol. 1991;22(7):674-84.

8. Miyagi J, Tsuhako K, Kinjo T, Iwamasa T, Hashimoto H, Ishikawa S. Rhabdoid tumour of the lung is a dedifferentiated phenotype of pulmonary adenocarcinoma. Histopathology. 2000;37(1):37-44.

9. Wang W, Xue Y, Zhou S, Kuo A, Cairns BR, Crabtree GR. Diversity and specialization of mammalian SWI/SNF complexes. Genes Dev. 1996;10(17):2117-30.

10. Schnitzler G, Sif S, Kingston RE. Human SWI/SNF interconverts a nucleosome between its base state and a stable remodeled state. Cell. 1998;94(1):17-27. 
11. Biegel JA, Zhou JY, Rorke LB, Stenstrom C, Wainwright LM, Fogelgren B. Germ-line and acquired mutations of INI1 in atypical teratoid and rhabdoidtumors. Cancer Res. 1999;59(1):74-9.

12. Cho IJ, Kim SS, Min YD, Noh MW, Hong R. Poorly differentiated cecal adenocarcinoma showing prominent rhabdoid feature combined with appendiceal mucinous cystadenoma: a case report and review of the literature. OncolLett. 2015;9(4):1527-30.

13. Chetty R, Bhathal PS. Caecal adenocarcinoma with rhabdoid phenotype: an immunohistochemical and ultrastructural analysis. Virchows Arch APatholAnatHistopathol. 1993;422(2):179-82.

14. Yang $\mathrm{AH}$, Chen WY, Chiang H. Malignant rhabdoid tumour of colon. Histopathology. 1994;24(1):89-91.

15. Macak J, Kodet R. Rectal adenocarcinoma with rhabdoid phenotype. Pathologica. 1995;87(6):696-9.

16 Marcus VA, Viloria J, Owen D, Tsao MS. Malignant rhabdoidtumor of the colon. Report of a case with molecular analysis. Dis Colon Rectum. 1996;39(11):1322-6.

17. Nakamura I, Nakano K, Nakayama K, Ishii Y, Ohta K, Takahashi M, et al. Malignant rhabdoidtumor of the colon: report of a case. Surg Today. 1999;29(10):1083-7.

18. Horie Y, Kato M, Umeki K, Maruyama S. A case of rectal adenocarcinoma with rhabdoid phenotype and neuroendocrine differentiation. J Okayama SurgPathol Assoc. 2000;37(1-2):15-20.

19. Hamada TSS, Nihira Y, Kobayashi N, Masako M, Sakurai S. A malignant rhabdoidtumor originating from the rectum. J ClinSurg. 2004;59(1):83-6.

20 Nakayama A, Tsujimoto K, Ito N, Takeuchi N, Matsushita M, Takashi E. A case of malignant rhabdoid tumor of the rectum. Jpn J Gastroenterol Surg. 2005;38(10):1630-5.

21. Matsunuma R, Kashiwabara H, Shuno H, Tochikubo J, Mano Y, Setoguchi T, et al. A case of malignant rhabdoidtumor of the ascending colon. Shizuoka J Med. 2005;19(1):91-5.

22. Yamaguchi R, Fujiki K, Akagi Y, Murakami N, Matsumoto A, Kofuji K, et al. Poorly differentiated adenocarcinoma of the colon with prominent rhabdoid features. Jpn J DiagnPathol. 2006;23(2):124-7.

23. Mastoraki A, Kotsilianou O, Papanikolaou IS, Foukas PG, Sakorafas G, Safioleas M. Malignant rhabdoidtumor of the large intestine. Int J Colorectal Dis. 2009;24(11):1357-8.

24. Han SL, Li JL, Liu Z, Cheng J, Guo SC, Wu SL. Malignant rhabdoidtumor of rectum: report of a case. Tech Coloproctol. 2010;14(2):199-200.

25. Pancione M, Di Blasi A, Sabatino L, Fucci A, Dalena AM, Palombi N, et al. A novel case of rhabdoid colon carcinoma associated with a positive CpG island methylator phenotype and BRAF mutation. Hum Pathol. 2011;42(7):1047-52

26. Takeshita M, Kadoya N, Syouji M, Amaya K, Yoshikawa A, Nojima N, et al. A case of giant rectal cancer with rhabdoid feature. Jpn J GastroenterolSurg. 2011;44(2):193-9.

27. Remo A, Zanella C, Molinari E, Talamini A, Tollini F, Piacentini P, et al. Rhabdoid carcinoma of the colon: a distinct entity with a very aggressive behavior: a case report associated with a polyposis coli and review of the literature. Int J SurgPathol. 2012;20(2):185-90.

28. Kobayashi Y, Yokoyama K, Goto T, Tanaka Y, Higashino M, Harada T, et al. Adenocarcinoma with extensive rhabdoid features (composite rhabdoidtumor) of the colon: a case report and review of the literature. Med J Minami Osaka Hosp. 2011;59(1):51-63.

29. Lee SH, Seol H, Kim WY, Lim SD, Kim WS, Hwang TS, et al. Rhabdoid colorectal carcinomas: reports of two cases. Korean J Pathol. 2013;47(4):372-7.

30. Samalavicius NE, Stulpinas R, Gasilionis V, Baltruskeviciene E, Aleknavicius E, Mickys U. Rhabdoid carcinoma of the rectum. Ann Coloproctol. 2013;29(6):252-5.

31. Saito K, Munemoto Y, Takashima Y, Suzuki H, lida Y, Mitui T, et al. A case of ascending colon cancer rapid growth and various histological types. J JpnSurgAssoc. 2014;75(7):1933-7.

32. Baba Y, Uchiyama T, Hamada K, Ishihara Y, Tanaka H, Isono Y, et al. A case report of undifferentiated carcinoma of the sigmoid colon with rhabdoid features. Nihon ShokakibyoGakkaiZasshi. 2014;111(7):1384-90.

33. Romera Barba E, Sanchez Perez A, Duque Perez C, Garcia Marcilla JA, Vazquez Rojas JL. Malignant rhabdoidtumor of the colon: a case report. Cir Esp. 2014;92(9):638-40.

34. Moussaly E, Atallah JP. A rare case of undifferentiated carcinoma of the colon with rhabdoid features: a case report and review of the literature. Case Rep Oncol Med. 2015;2015:531348.

35. Kalyan A, Pasricha G, Monga D, Singhi A, Bahary N. Case report of rhabdoid colon cancer and review of literature. Clin Colorectal Cancer. 2015;14(1):e5-8.

36. D'Amico F, Bertacco A, Cesari M, Mescoli C, Caturegli G, Gondolesi G, et al. Extraordinary disease-free survival in a rare malignant extrarenalrhabdoidtumor: a case report and review of the literature. J Med Case Rep. 2018;12(1):39.

37. Davies H, Bignell GR, Cox C, Stephens P, Edkins S, Clegg S, et al. Mutations of the BRAF gene in human cancer. Nature. 2002;417(6892):949-54.

38. Sanz-Garcia E, Argiles G, Elez E, Tabernero J. BRAF mutant colorectal cancer: prognosis, treatment, and new perspectives. Ann Oncol. 2017:28(11):2648-57.

39. Haydon AM, Jass JR. Emerging pathways in colorectal-cancer development. Lancet Oncol. 2002;3(2):83-8.

40. Kuwahara Y, Hosoi H, Osone S, Kita M, lehara T, Kuroda H, et al. Antitumor activity of gefitinib in malignant rhabdoidtumor cells in vitro and in vivo. Clin Cancer Res. 2004;10(17):5940-8.

\section{Publisher's Note}

Springer Nature remains neutral with regard to jurisdictional claims in published maps and institutional affiliations.

\section{Submit your manuscript to a SpringerOpen ${ }^{\circ}$ journal and benefit from:}

- Convenient online submission

- Rigorous peer review

- Open access: articles freely available online

- High visibility within the field

- Retaining the copyright to your article

Submit your next manuscript at springeropen.com 